\title{
Qualidade do ovo de galinhas poedeiras criadas em galpões no semi-árido paraibano ${ }^{1}$
}

\author{
$\overline{\text { Jair L. Trindade }}{ }^{2}$, José W. B. Nascimento ${ }^{3}$ \& Dermeval A. Furtado ${ }^{3}$
}

\begin{abstract}
RESUMO
Avaliar índices ambientais dos galpões e os zootécnicos em aves de postura leve da linhagem Lohamann, em condições de verão e inverno de 2005 na região do semi-árida paraibana, foi o objetivo primordial deste trabalho, no qual se utilizaram 34.500 aves com diferentes idades: 32, 50, 60 e 71 semanas, acondicionadas em quatro galpões. Avaliaramse os índices ambientais temperatura do ar, umidade relativa do ar, índice de temperatura do globo negro e umidade, carga térmica de radiação e velocidade do vento; e os produtivos (produção total de ovos, peso do ovo, peso do albúmen, peso da gema e peso das cascas), parâmetros geométricos (área e volume) e a unidade Haugh (UH) do ovo, em função da idade. Quanto ao ambiente no interior dos aviários, não houve diferença significativa na media dos índices ambientais, que ficaram dentro da zona de conforto. A idade das aves teve influência nos índices produção total, peso do ovo e peso da gema. A maior produção foi obtida com aves mais jovens, enquanto o peso do ovo e da gema foi com aves de maior idade. Os parâmetros geométricos volume e área do ovo não foram influenciados pela idade das aves. Conforme a UH os ovos de melhor qualidade se referem aos das aves com 32 e 50 semanas.
\end{abstract}

Palavras-chave: índices zootécnicos, parâmetros geométrico do ovo, unidade Haugh

\section{Quality of eggs of laying hens reared in poultry houses in the semi-arid Paraiba}

\begin{abstract}
The objective of this research was to evaluate production indexes for laying hens of the Lohamann lineage, under the summer and winter conditions of 2005, in São José da Mata district of Campina Grande, which is located in the Paraíban semi-arid region. 34.500 hens were used with ages of 32, 50, 60 and 71 weeks, and which were reared in four poultry houses. The production indexes (total production of eggs, egg weight, albumen weight, egg yolk weight, and rinds weight), geometric parameters (area and volume) and Haugh unit of egg were calculated as a function of hen age. The production indexes in all rearing systems followed the technical recommendations. The age of the hens influenced the indexes of total production, egg weight and also egg yolk weight. The highest production of eggs was obtained with the youngest birds. On the other hand, egg weight and the egg yolk weight were obtained with the oldest birds. The geometric parameters (volume and area) were not influenced by the age of the hens. According to Haugh unit index, the best evaluated hen eggs were the ones that were between 32 and 50 weeks.
\end{abstract}

Key words: production index, egg geometric parameters, Haugh unit

1 Trabalho extraído da Dissertação de Mestrado do primeiro autor

2 CEFET/RR Av. Glaycon de Paiva 2496, CEP 69303-340, Pricumã, Boa Vista, RR. Fone: (95) 3621-8000. E-mail: jairlt@gmail.com

3 UAEAg/UFCG. Fone: (83) 3310-1486. E-mail: wallace@deag.ufcg.edu.br; dermeval@deag.ufcg.edu.br 


\section{INTRODUÇÃO}

Atualmente, a avicultura de postura apresenta-se bem tecnificada, a maioria das granjas caminha para uma automatização completa dos seus processos de produção e a genética é a maior responsável pelas altas produções alcançadas pelas galinhas. Neste contexto, a qualidade da produção é um dos principais interesses dos produtores e consumidores de ovos, uma vez que está diretamente relacionada a fatores, como: higiene, sanidade e, principalmente, à saúde e bem-estar animais.

A classificação dos ovos por peso varia muito de país para país. Em vários mercados, incluindo Japão, México e Suécia, os ovos são vendidos por peso $(\mathrm{kg})$, ainda assim, o peso pago por quilograma varia com o peso médio de cada ovo. Muitos varejistas exigem uma proporção de ovos de cada tipo para atender às preferências de todos os seus clientes. No Brasil, os ovos são classificados em grupos, classes e tipos, segundo a coloração da casca, qualidade e peso, de acordo com as especificações.

Fatores como fisiologia da ave, tempo de oviposição, estrutura da gaiola, número de fêmeas por gaiola e freqüência de colheita de ovos, idade das aves, nutrição, condições de manejo, estado sanitário, temperatura e umidade, genética e manejo das aves, influenciam o tamanho e a qualidade do ovo (Andriguetto et al., 1998).

A integridade da casca tem grande influência na qualidade do ovo, sendo um dos fatores que mais têm preocupado os produtores, principalmente quando se explora a produção de ovos por mais um ciclo de postura. A espessura da casca pode variar devido a vários fatores, entre eles a hereditariedade, já que algumas famílias ou linhagens de aves produzem ovos com casca mais grossa que outras. Essas diferenças entre as aves, com relação à qualidade da casca, são definidas pela capacidade das aves de utilizarem o cálcio; outro fator é o clima, já que altas temperaturas reduzem a espessura da casca e os níveis de cálcio ou bicarbonato de sódio do sangue são reduzidos como resultado dos movimentos respiratórios mais acelerados, visto que as aves procuram, desta forma, controlar a temperatura corporal. Simultaneamente, o ambiente de temperatura elevada provoca diminuição no consumo de alimentos que, por sua vez, determina uma diminuição no consumo de cálcio, fósforo e vitamina $\mathrm{D}_{3}$. A avaliação da qualidade da casca tem sido feita por vários processos, diretos e indiretos destacando-se, neste último, o método do peso específico pela simplicidade, facilidade e rapidez, baixo custo, sem perda de ovos, sendo este o método indireto mais usado (Hamilton, 1982).

A idade da ave afeta a espessura da casca, sendo que as cascas mais finas aparecem depois de 10-12 meses de postura. O nível nutricional também interfere, uma vez que a casca do ovo é formada, sobretudo, de carbonato de cálcio e uma deficiência deste elemento pode resultar em ovos de casca mole ou casca fina, também a redução de magnésio e fósforo provoca a mesma situação (El Boushy \& Raterink, 1985).

Apesar da maior ênfase dada, ao peso do ovo na comercialização, o conhecimento da forma geométrica é de interesse da indústria avícola. Narushim (2005) diz que o cál- culo geométrico do ovo inclui a estimativa do volume e da área superficial, as quais são de grande importância, tanto para a indústria avícola como para estudos biológicos, como características da casca, parâmetros internos dos ovos e tamanho das pintainhas.

Um fator mundialmente conhecido para se avaliar a qualidade dos ovos é a unidade Haugh. Segundo Barbosa Filho (2004) trata-se de uma expressão matemática que correlaciona o peso do ovo com a altura da clara espessa, sendo que, de modo geral, quanto maior o valor da unidade Haugh melhor a qualidade do ovo.

O desconforto térmico em aves de postura também provoca uma série de conseqüências que, por sua vez, estão intimamente ligadas à queda no consumo de ração, menor taxa de crescimento, maior consumo de água, aceleração do ritmo cardíaco, alteração da conversão alimentar, queda na produção de ovos e maior incidência de ovos com casca mole. Normalmente, a temperatura normal do corpo de uma ave poedeira é, em média, $41^{\circ} \mathrm{C}$, sendo que, durante os dias de calor, a temperatura pode atingir até $43^{\circ} \mathrm{C}$; a partir daí, o animal está sujeito ao estresse térmico e para cada grau acima deste valor o consumo de alimentos começa a diminuir e a produção ficará comprometida (Nakano, 1979).

Segundo Ferreira (2005) a temperatura do aviário para aves adultas poderá oscilar entre 15 e $28{ }^{\circ} \mathrm{C}$, com a umidade relativa do ar variando entre de 40 a $80 \%$ e uma velocidade do vento entre 0,2 a 3,0 $\mathrm{m}^{-\mathrm{s}}$. Baeta \& Souza (1998) descrevem que ITGU variando ate 74 é seguro e entre 74 e 78 exigem certos cuidados. Em trabalho realizado por Rosa (1984) foram obtidos, às 14 horas, em um dia típico de céu claro com 12,3 horas de insolação, em Viçosa, MG, valores de CTR de 515,4 $\mathrm{W} \mathrm{m}^{-2}$ para galpões com telhas de cimento amianto e 498,3 $\mathrm{W} \mathrm{m}^{-2}$ para telhas de barro (francesa).

Objetivou-se, com este estudo, analisar os índices ambientais (temperatura do ar, umidade relativa do ar, índice de temperatura do globo negro e umidade, carga térmica de radiação e velocidade do vento), produtivos (produção total de ovos, peso do ovo, peso do albúmen, peso da gema, peso das cascas) e parâmetros geométricos (área e volume) e a unidade Haugh do ovo em função da idade das aves alojadas.

\section{MATERIAL E MÉTODOS}

A fase experimental deste trabalho foi realizada em galpões de criação comercial de galinhas poedeiras, pertencente à Granja Bosque da Prata, localizada no Distrito de São José da Mata, Município de Campina Grande, PB, inserida no semi-árido paraibano, com altitude de $548 \mathrm{~m}$, com latitude de $07^{\circ} 11^{\prime}$ 23”' Sul e longitude de $35^{\circ}$ 59' 04” Oeste. De acordo com a classificação climática de Koeppen, o clima da região é AWi, caracterizado como clima tropical chuvoso (megatérmico) com total anual médio de chuva (P) em torno de $750 \mathrm{~mm}$ e temperatura do ar média mensal em todos os meses superior a $18^{\circ} \mathrm{C}$, em que a estação seca se caracteriza do inverno à primavera.

O experimento foi conduzido em quatro galpões de postura de um mesmo núcleo, nos meses de maio e junho de 
2005, quando se utilizaram 34.500 aves da linhagem Lohmann (leves), com idade no intervalo de 32 a 71 semanas. A Granja Bosque da Prata tem produção diária aproximada de 22.500 ovos.

Os galpões estão orientados no sentido leste-oeste, construídos em alvenaria com comprimento de $57 \mathrm{~m}$, largura 7,20 m, altura de pé-direito de 2,60 m, constituindo uma área de $410,40 \mathrm{~m}^{2}$; o piso interno e o passeio são de solo cimento, além de comedouro manual e bebedouro tipo nipple.

O telhado do galpão tem cobertura de telha ondulada de cimento amianto, com $6 \mathrm{~mm}$ de espessura, apoiado sobre treliças de madeira, em duas águas, com inclinação de $20^{\circ}$ e beiral de 1,10 m de comprimento.

A alimentação era distribuída manualmente em todos os galpões, a partir das 5 h, com média de $360 \mathrm{~kg}$ por aviário. Os aviários possuem dois vãos com duas baterias de gaiola, cada uma com três andares e dimensões de 50 x 45 x 45 cm com capacidade para cinco aves, além de comedouros tipo calha e bebedouros tipo nipple acoplados às gaiolas. A ração era à base de proteínas, carboidratos, lipídeos, vitaminas e minerais considerados de grande importância na alimentação das aves, visto que, participam de todos os processos bioquímicos corporais, dentre os quais se destaca a importância dos minerais na formação da casca do ovo e na melhora da sua qualidade interna. Durante a fase do experimento todas as aves tiveram o mesmo manejo, receberam formulação de ração idêntica, de acordo com a idade de cada lote.

O registro dos índices ambientais foi coletado a cada duas horas, no intervalo das 8 às 16 h, sendo realizadas as seguintes medições: temperatura do ar (TA), umidade relativa do ar (UR) e velocidade do vento ( $\mathrm{Vv}$ ), realizadas através de um termo-higro-anemômetro (LM - 8000 Lutron), com precisão de duas casas decimais, coletados em três pontos dos aviários, no inicio, meio e fim, sendo feita uma media destes dados, e o sensor estava colocado no centro de massa das aves de cada galpão pesquisado.

Registrou-se também a temperatura de globo negro, por meio de termômetros de globo negro, com diâmetro de $0,15 \mathrm{~m}$, onde estava inserido um termômetro de mercúrio com resolução de $0,1^{\circ} \mathrm{C}$, utilizando a mesma metodologia dos outros índices ambientais. Com esses dados calculou-se os valores do índice de temperatura do globo negro e umidade (ITGU) e da carga térmica de radiação (CTR), nos horários considerados.

A avaliação do desempenho zootécnico das aves em função das idades, se deu por meio dos índices de desempenho produtivo, dos parâmetros geométricos do ovo e da unidade Haugh.

a) Índices produtivos: Foram coletadas, manualmente, amostras de 30 ovos por galpão, acondicionados em bandejas, sempre no mesmo horário $(8 \mathrm{~h})$, por um período de seis semanas, sendo que as bandejas eram transportadas imediatamente da granja para o Laboratório de Construções Rurais e Ambiência da UFCG, para realização das analises. Foi avaliada a produção total de ovos (PT), em relação à quantidade de aves mantidas em cada galpão; peso do ovo (PO), que foram pesados em balança digital com precisão de $0,01 \mathrm{~g}$ e retiradas suas médias; peso da casca (PC) após a retirada dos componentes; as cascas foram secas a $105^{\circ} \mathrm{C}$ durante o período de $2 \mathrm{~h}$ e pesadas em balança digital com precisão de 0,01 g; peso do albúmen (PA), após a separação dos componentes (casca e gema); peso da gema (PG), depois de retirada do albúmen e da chalaza;

b) Como parâmetros geométricos, determinaram-se volume (V) e a área do ovo (S), segundo metodologia de Narushim (2005), conforme as Eq. 1 e 2.

$$
\begin{aligned}
& V=(0,6057-0,0018 d) D d^{2} \\
& S=(3,155-0,0136 D+0,00155 d) D d
\end{aligned}
$$

em que:

$$
\text { d - diâmetro menor do ovo, cm }
$$$$
\text { D - diâmetro maior do ovo, cm }
$$

c) Unidade Haugh

Para determinação da unidade Haugh utilizou-se de uma amostra aleatória de trinta ovos em cada galpão, realizada no dia 21/06/2005; após a pesagem, os ovos foram quebrados e seu conteúdo (albúmen + gema), colocado em uma superfície de vidro, plana e nivelada; mediu-se, então, a altura do albúmen (mm), por meio da leitura do valor indicado pelo micrômetro; de posse dos valores de peso do ovo (g) e altura do albúmen (mm) utilizou-se, então, a fórmula descrita por Barbosa Filho (2004), para o cálculo da unidade Haugh (Eq. 3):

$$
\mathrm{UH}=100 \log \left(\mathrm{h}+7,57-1,7 \mathrm{~W}^{0,37}\right)
$$

onde:

$$
\begin{aligned}
& \text { h - altura do albúmen, mm } \\
& \text { W - peso do ovo, g }
\end{aligned}
$$

Para a análise de variáveis zootécnicas, produção total de ovos, peso dos ovos, percentagem de gema, de albúmen e das cascas, utilizou-se um delineamento em blocos casualizados composto de quatro tratamentos (aves com 32, 50, 60 e 71 semanas) e nove blocos (época de coleta). Para os índices geométricos (volume e área) os blocos se compuseram de cinco épocas de coleta.

\section{RESULTADOS E DISCUSSÃO}

\section{Índices ambientais e produtivos}

Quanto ao ambiente no interior dos aviários, não houve diferença significativa na temperatura media do ar (TA), umidade relativa do ar (UR) e índice de temperatura do globo negro e umidade (ITGU), carga térmica de radiação (CTR) e velocidade do vento ( $\mathrm{Vv}$ ), que foram de $27,7^{\circ} \mathrm{C}$; $65,1 \%$; 75,$61 ; 460,4 \mathrm{~W} \mathrm{~m}^{-2}$ e de $0,30 \mathrm{~m} \mathrm{~s}^{-1}$, respectivamente. Estes valores podem ser considerados como dentro da zona de conforto térmico para aves de postura (Baeta \& Souza, 1997; Silva, 2000; Ferreira, 2005).

Analisando-se a idade das aves, observa-se na Tabela 1 , efeito altamente significativo $(\mathrm{P}<0,01)$ nos valores de peso total, peso do ovo e gema e não influenciou nos valores de 
albúmen e casca; já com relação aos blocos, só não se observou efeito significativo nos resultado das cascas. Tinôco (1996) pesquisando aves de postura entre 26 e 37 semanas, encontrou efeito altamente significativo tanto para os diferentes sistemas de acondicionamento de ambiente como para a idade, nos valores de produção total de ovos por ave alojada.

Conforme os baixos valores de coeficientes de variação encontrados, o experimento pode ser considerado de alta precisão, segundo Gomes (2000).

Tabela 1. Resumo das análises de variância referentes aos efeitos dos tratamentos (idade das aves em semanas) nos valores médios da produção total (PT), peso do ovo (PO), peso do albúmem, peso da gema (PG) e peso das cascas (PC)

\begin{tabular}{lrrrrrr}
\hline \multirow{2}{*}{ F.V. } & \multirow{2}{*}{ G.L. } & \multicolumn{5}{c}{ QUADRADOS MÉDIOS } \\
\cline { 3 - 8 } & & PT & PO & ALBÚMEM & GEMA & CASCA \\
Trat $(\mathrm{I})$ & 3 & $162,85^{* *}$ & $49,24^{* *}$ & $0,18^{\text {ns }}$ & $1,43^{* *}$ & $0,32^{\text {ns }}$ \\
Bloco & 8 & $1,69^{*}$ & $6,96^{* *}$ & $0,92^{*}$ & $0,59^{*}$ & 0,9 ns \\
Resíduo & 24 & 0,54 & 1,71 & 0,33 & 0,25 & 0,18 \\
C.V (\%) & & 0,82 & 2,05 & 0,90 & 1,88 & 4,33 \\
\hline$* *$
\end{tabular}

**F significativo a nível de $1 \%$ de probabilidade; ${ }^{\star} F$ significativo a nível de $5 \%$ de probabilidade

Os valores médios dos índices produtivos são visualizados na Tabela 2, na qual se constata, pelo teste de Tukey, diferença estatística para os valores de produção total entre os diferentes tratamentos; assim, a maior produção, 93,55\%, ocorreu nas aves com 32 semanas; percentualmente à menor produção, ocorreu nas aves com 71 semanas $(83,44 \%)$ diferindo estatisticamente das demais. Quanto mais velhas as aves, menor a produção total. Tinôco (1996) pesquisando aves de postura entre 26 e 37 semanas sob diferentes sistemas de acondicionamento de ambientes e diferentes níveis de energia metabolizável na dieta de matrizes, notou valores de PT crescentes até a $35^{\mathrm{a}}$ semana, quando se deu o pico de postura, decrescendo a partir daí; efeito semelhante se constatou no presente estudo quando a produção decresceu a partir da $44^{\mathrm{a}}$ semana.

Tabela 2. Valores médios dos índices zootécnicos produção total de ovos (PT), peso do ovo, peso do albúmen, peso da gema e peso das cascas, em função dos tratamentos idade das aves, em semanas

\begin{tabular}{lccccc}
\hline \multirow{2}{*}{ Tratamentos } & PT & Peso & Albúmem & Gema & Casca \\
\cline { 3 - 6 } & $\mathbf{( \% )}$ & \multicolumn{4}{c}{$\mathbf{( g )}$} \\
32 semanas & $93,55 \mathrm{~d}$ & $60,52 \mathrm{~b}$ & $38,62 \mathrm{a}$ & $15,85 \mathrm{a}$ & $6,05 \mathrm{a}$ \\
\hline 50 semanas & $90,66 \mathrm{c}$ & $64,45 \mathrm{~b}$ & $41,17 \mathrm{a}$ & $17,00 \mathrm{a}$ & $6,28 \mathrm{a}$ \\
60 semanas & $89,00 \mathrm{~b}$ & $65,60 \mathrm{~b}$ & $41,66 \mathrm{a}$ & $17,71 \mathrm{~b}$ & $6,23 \mathrm{a}$ \\
71 semanas & $83,44 \mathrm{a}$ & $65,50 \mathrm{~b}$ & $41,95 \mathrm{a}$ & $17,23 \mathrm{a}$ & $6,32 \mathrm{a}$ \\
\hline
\end{tabular}

As médias seguidas de pelo menos uma mesma letra, na coluna, não diferem entre si, a nível de $5 \%$ de probabilidade pelo Teste de Tukey

Costa \& Jácome (2004) trabalhando com poedeiras da linhagem Hisex Brown com idade de 40 semanas, encontraram produção com média de $86,00 \%$ em condições de verão, na cidade de Areia, $\mathrm{PB}$, alojadas em galpão aberto com cobertura de palha. Jácome (2005) relatou valores médios de produção total para o sistema telha de cimento-amianto de $87,20 \%$ e, para o sistema telha de cerâmica, de $90 \%$. Farias et al. (2005) observaram que aves mais velhas produziram menos ovos, apresentaram maior peso dos ovos e pior conversão alimentar em relação às aves mais jovens; ele descreve, ainda, para aves com idade entre 24-36 semanas, 92,86 \% de produção total de ovos.

Os dados constantes na Tabela 2 para aves com 32 semanas, estão coerentes com os valores recomendados pelo Guia de Manejo Lohmann, Hy-Line do Brasil (2005) que apresenta como média para aves da linhagem Lohmann com 32 semanas, PT de 94,5\%; no entanto, o mesmo manual mostra valores de PT de 79,5 para aves com 71 semanas, diferindo do encontrado nesta pesquisa, que foi de 83,44.

Quanto ao peso do ovo vê-se, na Tabela 2, diferença estatística para os valores de peso dos ovos entre os diferentes tratamentos. O maior peso encontrado foi de 65,60 g, nas aves com 60 semanas, porém não diferem estatisticamente das aves com 50 e 71 semanas; já o menor, 60,52 g, foi encontrado nas aves com 32 semanas, diferindo estatisticamente dos demais. Segundo classificação do Guia de Manejo Lohmann (2005) os ovos das aves com 60, 50 e 71 semanas são classificados como grandes, enquanto as aves com 32 semanas como ovos médios, ainda de acordo com o mesmo guia de manejo, a meta de desempenho da linhagem Lohmann para 32, 50, 60 e 71 semanas, os ovos devem pesar 60,8; 64,1; 65,1 e 66,2 g, respectivamente; portanto, os valores encontrados na pesquisa estão coerentes com o previsto para raça e idade das aves.

Jácome (2005) mostrou valores médios de peso do ovo para galpões com telha de cimento-amianto, de 66,38 g e telha de cerâmica, de 71,54 g. Silversides \& Scott (2001) mostraram valores abaixo da média, descritos nesta pesquisa para peso do ovo, para a linhagem ISA Brown, com média de peso de $58,5 \mathrm{~g}$.

De acordo com a Tabela 2, dos constituintes albúmen, gema e casca, observa-se que a diferença estatística foi a nível de 5\% pelo teste de Tukey, somente nas médias do peso da gema. O maior peso de gema encontrado foi de $17,71 \mathrm{~g}$, nas aves com 60 semanas, diferindo estatisticamente das aves com 32, 50 e 71 semanas; não ocorreu, porém diferença estatística entre as médias de peso de gema para as galinhas com 32, 50 e 71 semanas. Os valores estão coerentes com os indicados por Jácome (2005), ou seja, valores médios de peso de gema, para coberturas com telha de amianto de 17,51 g e, para coberturas com telha de cerâmica, de 18,33 g. Avaliando os efeitos da idade das poedeiras (25, 31, 49 e 59 semanas) das linhagens ISA Brown e ISA White sobre a proporção dos componentes dos ovos, Silversides \& Scott (2001) constataram que o peso do ovo e a porcentagem de gema aumentam com a idade enquanto a casca e o albúmen diminuem.

Em relação à Tabela 2 e se relacionando o peso da gema com o peso do albúmen, encontram-se os seguintes valores: aves com 60 semanas 0,42 ; aves com 32 semanas 0,41 ; aves com 50 semanas 0,41 e aves com 71 semanas 0,42 ; portanto, quanto maior a idade da ave maior tamanho a relação gema/albúmen. Ahn et al. (1997) estudaram os efeitos do tamanho do ovo e da idade da poedeira sobre o conteúdo de sólidos totais do ovo, do albúmen e da gema e verificaram 
que, quanto maior o tamanho dos ovos menor é a relação gema/albúmen, considerando-se que os maiores valores desta relação foram observados em poedeiras com idade de 55 e 78 semanas; recomenda-se que esses ovos sejam utilizados na indústria de processamento, enquanto os das poedeiras de 28 e 97 semanas (após a muda forçada) são mais indicados para consumo.

A relação, em percentagem, entre peso da casca e peso do ovo, a partir da Tabela 2, é 9,5; 10,0; 9,7 e 9,6\% para as aves com 60, 32, 50 e 71 semanas, respectivamente. Considerando-se que as aves estudadas se encontravam acondicionadas em galpões com telha de fibrocimento, os valores da percentagem de casca se assemelham aos encontrados por Jácome (2005) que encontrou valores de percentagem de casca, para coberturas com telha de amianto, de 9,4\% e, para telha de cerâmica, de 8,8\%. Barbosa Filho (2004) encontrou porcentagens de casca de ovos de aves submetidas a estresse térmico, na ordem de 8,6\% para a linhagem Brown, valor este menor que os encontrados na presente pesquisa. Hamilton (1982) comenta que um aspecto que se deve ter em conta é que as galinhas tendem a produzir ovos com casca de qualidade inferior, a medida que se tornam mais velhas devido, entre outras causas, ao fato de que os ovos são de maior tamanho e apresentam menor proporção da casca.

\section{Parâmetros geométricos}

Nota-se, na Tabela 3, que o efeito dos tratamentos idade das aves proporcionou efeito significativo $(\mathrm{P}<0,05)$ nos valores do volume e outro altamente significativo $(\mathrm{P}<0,01)$ nos valores da área do ovo. Conforme os baixos valores de coeficientes de variação encontrados, o experimento pode ser considerado de alta precisão, segundo Gomes (2000).

Os valores médios dos parâmetros geométricos do ovo, volume e área, para os diferentes tratamentos, são visualizados na Tabela 4. Conforme o teste de Tukey foi clara a diferença estatística para os valores médios dos dois parâmetros analisados; desta forma, o maior volume médio se destacou

Tabela 3. Resumo das análises de variância referentes aos efeitos dos tratamentos (idade das aves em semana) nos valores médios do volume e da área do ovo

\begin{tabular}{|c|c|c|c|}
\hline \multirow{2}{*}{ F.V. } & \multirow{2}{*}{ G.L. } & \multicolumn{2}{|c|}{ Quadrados médios } \\
\hline & & Volume & Área \\
\hline Trat (I) & 3 & $44,90 *$ & 33,96 ** \\
\hline Bloco & 4 & $19,78^{\text {ns }}$ & $9,41^{\mathrm{ns}}$ \\
\hline Resíduo & 12 & 8,74 & 4,63 \\
\hline C.V (\%) & & 4,30 & 2,70 \\
\hline
\end{tabular}

${ }^{\star *} \mathrm{~F}$ significativo a nível de $1 \%$ de probabilidade; ${ }^{*} \mathrm{~F}$ significativo a nível de $5 \%$ de probabilidade

Tabela 4. Valores médios dos parâmetros geométricos volume e área do ovo, em função dos tratamentos idade das aves em semanas

\begin{tabular}{ccc}
\hline Tratamentos & Volume $\left(\mathbf{c m}^{3}\right)$ & Área $\left(\mathbf{c m}^{2}\right)$ \\
32 semanas & $64,60 \mathrm{~b}$ & $76,30 \mathrm{~b}$ \\
50 semanas & $68,47 \mathrm{ab}$ & $79,26 \mathrm{ab}$ \\
60 semanas & $71,18 \mathrm{a}$ & $81,80 \mathrm{a}$ \\
71 semanas & $70,68 \mathrm{a}$ & $81,76 \mathrm{a}$ \\
\hline
\end{tabular}

As médias seguidas de pelo menos uma mesma letra, na coluna, não diferem entre si a nível de $5 \%$ de probabilidade, pelo teste de Tukey às aves com 60 semanas; no entanto, não difere estatisticamente do volume dos ovos das aves com 50 e 71 semanas diferindo; entretanto, das aves com 32 semanas; fenômeno semelhante se deu com o parâmetro área do ovo e, então, aves com 32 semanas, em média, proporcionaram ovos com volume e área menor. Mohsenin (1970) trabalhando com modelo elíptico encontrou valores médios de área de $70,5 \mathrm{~cm}^{2}$.

A relação entre peso e volume e peso e área, pode ser estudada para o ovo. Correlacionando-se os valores de volume (V) e de área (S) em função do peso (P) do ovo, concluise que o modelo matemático empírico que melhor se ajustou, em função do coeficiente de determinação, $\mathrm{R}^{2}$, foi o potencial, cujas equações são: $\mathrm{V}=1,09 \mathrm{P}^{0,99}$ e $\mathrm{S}=4,90 \mathrm{P}^{0,67}$. Besch et al., citado por Mohsenin (1970) encontraram o mesmo modelo empírico para estimar área de ovos, em que a constante da equação variou de 4,56 a 5,07, enquanto o expoente apresentou valor 0,66.

\section{Unidade Haugh}

Na Figura 1 se encontram os valores da unidade Haugh obtidos no experimento; pode-se observar que os valores diminuíram com o aumento da idade das aves corroborando com Fletcher et al. (1983) que mostram valores de unidades Haugh para ovos frescos, diminuindo com o aumento da idade das aves. Quanto maior o valor da unidade Haugh melhor será a qualidade dos ovos, que são classificados, segundo o USDA, em ovos tipo AA (100 até 72), A (71 até 60), B (59 até 30), C (29 até 0), USDA Egg-Grading Manual (2005). Mesmo com temperatura ambiente média de $28^{\circ} \mathrm{C}$ e condições de semi-aridez da região, no presente trabalho, apenas ovos das aves com idade de 71 semanas são classificados como A - ótimo e os demais com AA, ou seja, excelente qualidade. Valores maiores de unidade Haugh $(83,66 \pm 5,72)$ foram constatados por Alleoni \& Antunes (2001) trabalhando, também, com ovos de poedeiras da linhagem Lohmann, mas na região sudeste. Segundo os autores, a unidade Haugh diminuiu para 41,71 $\pm 4,01$ quando armazenados durante sete dias a uma temperatura de $25^{\circ} \mathrm{C}$.

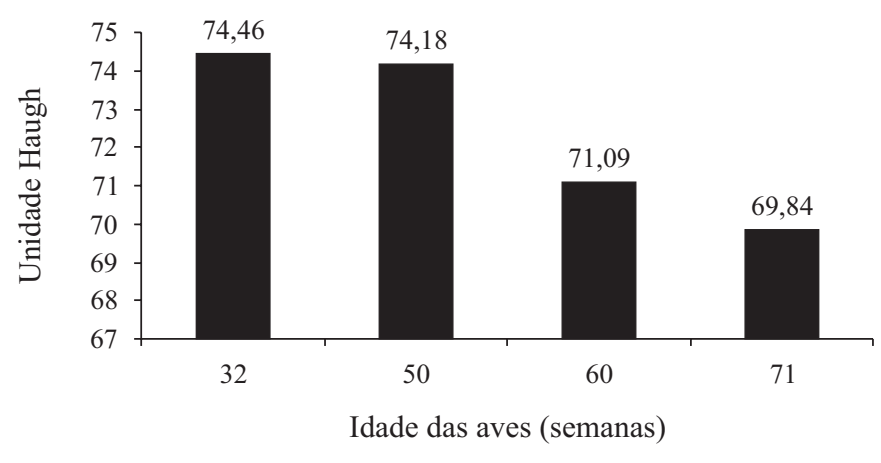

Figura 1. Unidade Haugh nos diferentes tratamentos (idade das aves em semanas)

\section{CONCLUSÕES}

1. Os valores dos índices produtivos em todas as idades das aves e sistemas de acondicionamento estão coerentes com as recomendações técnicas. 
2. A idade das aves influenciou nos índices produtivos: produção total, peso do ovo e peso da gema, nos parâmetros geométricos volume e área dos ovos.

3. A maior produção de ovos foi obtida com aves mais jovens, enquanto os pesos do ovo e da gema foram com aves de maior idade.

4. Quanto maior o peso do ovo maior também o volume e a área superficial do ovo.

5. De acordo com a unidade Haugh, os ovos estudados são classificados de ótimos a excelentes.

\section{AGRADECIMENTOS}

Ao CEFET-RR, pela liberação do primeiro autor, para realização do mestrado; à granja Bosque da Prata, por conceder suas instalações à presente pesquisa; ao CNPq, pela bolsa de produtividade em pesquisa concedida ao segundo autor e ao LaCRA/UFCG.

\section{LITERATURA CITADA}

Ahn, D. U; Kim, S. M.; Shu, H. Effect of egg size and strain and age of hens on the solids content of chicken eggs. Poultry Science, Savoy, v.76, p.914-919, 1997.

Alleoni, A. N.; Antunes, A. J. Unidade Haugh como medida de qualidade de ovos de galinha armazenados sob refrigeração. Scientia Agrícola, Piracicaba, v.58, n.4, p.681-685, 2001.

Andriguetto, J. M.; Perly, L; Minardi, I; Gemael, A; Flemming, J. S.; Souza, G. A.; Bona Filho, A. Nutrição animal: As bases e os fundamentos de nutrição animal. 6.ed. São Paulo: Nobel, 1998. 183p.

Baêta, F. C.; Souza, C. F. Ambiência em edificações rurais - conforto animal. Viçosa: UFV, 1997, 246p.

Barbosa Filho, J. A. Avaliação do bem-estar de aves poedeiras em diferentes sistemas de produção e condições ambientais, utilizando análise de imagens. Piracicaba: ESALQ/USP, 2004. 123p. Dissertação Mestrado

Costa, F. G. P; Jácome, I. T. D. Níveis de fósforo disponível e de fitase na dieta de poedeiras de ovos de casca marrom. Ciência Animal Brasileira, Goiânia, v.5, n.2, p.73-81, 2004.
El Boushy, A. R. E; Raterink, R. Componentes do ovo. Avicultura Industrial, Porto Feliz, v.3, p.37-42, 1985.

Farias, D. E.; Santos, A. L. Exigências nutricionais de galinhas poedeiras. In: Simpósio Internacional sobre Exigências Nutricionais de Aves e Suínos, 2, 2005, Viçosa. Anais... Viçosa: UFV, 2005, p.315-330.

Ferreira, R. A. Maior produção com melhor ambiente para aves, suínos e bovinos. Viçosa: Aprenda Fácil, 2005, 317p.

Fletcher, D. L.; Britton, W. M.; Pesti, G. M.; Rahn, A. P. The relationship of layer flock age egg component yields and solids content. Poultry Science, Savoy, v.62, p.1800-1805, 1983.

Gomes, F. P. Curso de estatística experimental. 14.ed. Piracicaba: ESALQ/USP, 2000. 477p.

Hamilton, R. M. G. Methods and factors that affect the measurement of egg shell. Poultry Science, Savoy, v.61, p. 20222039, 1982.

Hy-Line do Brasil. Guia de manejo Lohmann clássica. http:// www.hylinedobrasil.com.br. 07 Nov. 2005.

Jácome, I. T. D. Efeitos de dois sistemas de acondicionamento sobre os índices ambientais e zootécnicos de poedeiras semi-pesadas. Campina Grande: UFCG, 2005. 81p. Dissertação Mestrado

Mohsenin, N. N. Physical properties of plant and animal materials. 2.ed. New York: Gordon and breach Science, 1970. 742p.

Nakano, M. Problemas da avicultura no verão. Avicultura Industrial, Porto Feliz, v.2, p.22-27, 1979.

Narushin, V. G. Egg geometry calculation using the measurements of length and breadth. Poultry Science, Savoy, v.84, p.482-484, 2005.

Rosa, Y. B. C. J. Influência de três materiais de cobertura no índice de conforto térmico em condições de verão, para Viçosa, MG. Viçosa: UFV, 1984. 77p. Dissertação Mestrado

Silva, R. G. Introdução à bioclimatologia animal. São Paulo: Nobel, 2000. 286p.

Silversides, F. G.; Scott, T. A. Effect of storage and layer age on quality of eggs from two lines of hens. Poultry Science, Savoy, v.80, p.1240-1245, 2001.

Tinôco, I. F. F. Efeito de diferentes sistemas de acondicionamento de ambiente e níveis de energia metabolizável na dieta sobre o desempenho de matrizes de frangos de corte, em condições de verão e outono. Belo Horizonte: UFMG, 1996. 173p. Tese Doutorado

USDA. Egg-grading manual. http://www.ams.usda.gov/poultry. 10 Nov. 2005. 